C2009 IEEE. Personal use of this material is permitted. However, permission to reprint/republish this material for advertising or promotional purposes or for creating new collective works for resale or redistribution to servers or lists, or to reuse any copyrighted component of this work in other works must be obtained from the IEEE. 


\title{
Special Session - Utopia University- Building a Roadmap for Educating the Next Millennium's Engineers
}

\author{
Euan Lindsay, Alan Cheville, Lisa Benson \\ e.lindsay@curtin.edu.au,kridnix@okstate.edu, lbenson@clemson.edu
}

\begin{abstract}
Ailing multibillionaire P. Oscar Utopia wishes to endow a university in honor of Rose B. Utopia, his beloved wife and long-practicing engineer. He will be at FIE to draw upon the expertise of our community to design the master plan for a university of the next millennium, unburdened by the assumptions of the present and the past. Conference attendees who subscribe to Utopia's vision are encouraged to participate in this workshop, challenge the assumptions inherent to the current practice, and brainstorm a plan for educating the engineer of 3030. During this session, we will identify and challenge assumptions that are inherent to the current practice of how we educate engineers. Participants will engage in a series of rapid planning sessions based on the "what if" scenario of being able to establish a new engineering school unfettered by standard constraints of money, facilities, or current educational practice
\end{abstract}

Index Terms - next-generation engineer, future of engineering education, engineer of 3030 .

\section{INTRODUCTION}

The organizers of this session are close personal friends with P. Oscar Utopia [1], an aging multi-billionaire interested in educational philanthropy. Oscar made his fortune in technology, assisted by his late beloved wife, Rose B. Utopia, a long-practicing engineer. Oscar will be at FIE and would like to draw upon the expertise of the community of engineering educators for help in designing the master plan for Utopia University, which he intends to be the university of the next millennium.

It is Oscar's wish that the university be unburdened by the assumptions inherent in the practices of present and past universities. Session participants will identify five priority areas (the "pillars") of this institution that will best prepare engineers to meet the challenges of the next millennium. Oscar defines these pillars as five areas around which Utopia University will be organized. Oscar has stressed that he is placing no restrictions on what these pillars should be, just that they must be identified by consensus of leading practicing engineering educators. Oscar also wishes the community to describe the characteristics of ideal candidates to lead further development efforts for each of the five pillars. "It is one thing to identify the key focus 978-1-4244-4714-5/09/\$25.00 C2009 IEEE areas for the vision for Utopia University," declared Utopia; "it is another to identify the characteristics of the individuals who are needed to realize my vision."

\section{BACKGROUND AND SESSION OBJECTIVES}

This FIE special session will enable participants to identify and challenge assumptions inherent to current practices of educating engineers. A decade or more of research on how engineering students learn has resulted in breakthroughs; there is consensus by experts on effective pedagogy. Although this consensus presents engineering educators with unprecedented opportunities, effective pedagogy is entering the classroom at a glacial pace. There is increasing concern [2, 3] that a decreasing number of technologically innovative graduates will result in declines in economic competitiveness. Are the meaningful, lasting, and sustainable changes that research in engineering education calls for feasible within the existing university structure?

This session will engage a broad group of engineering educators on this question of how we educate engineers, and identify five priority areas (the "pillars") of a fundamentally new institution that will prepare engineers to meet the challenges of the next millennium. The session will also describe ideal candidates for leading the realization of these priority areas.

\section{SESSION ACTIVITIES}

Just as P. Oscar Utopia wishes his University to be free of the assumptions of existing institutions, this special session will differ from "typical" FIE special sessions. Rather than requiring participants to work to the same timeline, the activities for this session will evolve throughout the ninety minutes.

The session will commence with an introduction from Mr. Utopia, who will spend five minutes outlining the goals of the session, and placing it in context.

Participants will then separate into three focus groups. Each group will initially address different areas: developing potential programs; the needed human resources; and the infrastructure and environment of the campus. Each group will first be asked to brainstorm to generate ideas for the university from the perspective of their group's focus area. Specifically groups will be asked to: 1) identify key ideas needed for educating engineers, 2) identify assumptions

October 18 - 21, 2009, San Antonio, TX 
Session M2A

inherent to these ideas, and then 3 ) decide whether to retain or discard these assumptions to create the five pillars Utopia University would be based on.

Ideas, once identified, will be posted on the walls of the meeting room for public display and commentary. As ideas are posted, all participants will be encouraged to identify assumptions inherent in the ideas by writing assumptions on the posted ideas. To stimulate participation, P. Oscar Utopia will reward participants with one "gold coin" from his vast collection each time they post an idea or identify assumptions inherent to a posted idea. The session facilitators will guide and challenge participants by encouraging them to work not only on their ideas, but also to review the ideas of others. Throughout this review process the groups will grow, shrink, move and split as different ideas draw more support or review.

When an idea draws sufficient support from a group of participants, they will be asked to put that idea forward in writing by completing a "Request for Pillar" (RFP) form, with title, description, job description and signatures of at least five supporters. Each group additionally identifies a lead "champion" to discuss, defend, and publicly present their RFP. Mr. Utopia will only accept RFPs from groups that have actively engaged in the assumption identification process; an RFP form costs three gold coins to submit.

As written RFP's are collected, they will be reviewed by the session moderators acting as Mr. Utopia's advisors. This process will merge similar ideas and select the five pillars that the new university will be founded on.

It is intended that the first ideas should be posted by around the 20 minute mark of the session, and that the first Request for Pillar will occur around the 40 minute mark. The session moderators will prompt the participants to ensure that progress is continuous; however good ideas will not be sacrificed for the sake of adhering to a timeline. The 60 minute mark of the session will be the deadline for submissions for RFPs. Shortly after this point, Mr. Utopia will announce the five successful pillars, and call upon the champion of each of the five selected RFP's (i.e. five pillars) to deliver short reports on the ideas, assumptions, and characteristics of the pillar and its ideal leader.

There will then be an open discussion by all participants on a comparison between the five pillars and current priorities identified by the engineering education community. Finally, Mr. Utopia will conclude the session with a vision of the future of Utopia University.

\section{Contributions to EngINEERING EdUCATION}

The special session is designed for the community of engineering educators, engineering education researchers, administrators, and graduate students to identify:

- Ideas from the engineering education community on what an ideal future engineering program should look like.

- Assumptions held by the community about the future of engineering education.
- Assumptions about the current practice of engineering education that, if discarded, could lead to improved educational outcomes

- Ideas for five or more emergent priorities, and job descriptions for future leaders, in engineering education.

These learning goals will be identified at the start of the session and participants will be surveyed immediately after the session as well as one month following the session to determine if the session enabled participants to rethink assumptions inherent to higher education.

To provide an archival record, this session will be recorded and then transcribed. Each participant will sign a study release form. All the ideas generated and the formal RFP's will be collected at the end of the session. The outcomes of this session will be analyzed to identify the priorities for engineering education that are currently emerging from the community of practitioners. These emergent priorities will be compared to those of universities, professional bodies, and accreditation boards.

\section{CONCLUSIONS}

It is important that scholarship in Engineering Education not lose sight of the ultimate goal of educating engineers. This special session is organized to help establish and frame a discussion on what the ultimate goal of educating engineers looks like to different members of the engineering education community. The community will identify path(s) to achieve this goal. The outcomes of this session and feedback from the community will be analyzed to determine alignment with, as well as divergence from, publicized goals of national-level panels and organization. The special session will help to drive the reflective process to collect ideas, identify the barriers inherent in our current practice, and to provide an agenda for overcoming them. This session will also identify characteristics of the leaders needed to create and support a long-term vision for engineering education.

\section{REFERENCES}

[1] P. Oscar Utopia is a fictional creation expressly created to contextualize discussion in this special session.

[2] Committee on Prospering in the Global Economy of the 21st Century, Rising Above the Gathering Storm: Energizing and Employing America for a Brighter Economic Future, National Academy Press, Washington, D. C., 2007.

[3] Committee on the Engineer of 2020, The Engineer of 2020: Visions of Engineering in the New Century, National Academy Press, Washington, D. C., 2004.

\section{AUTHOR INFORMATION}

Euan Lindsay, Senior Lecturer, Department of Mechanical Engineering, Curtin University of Technology, e.lindsay@curtin.edu .au

Alan Cheville, Associate Professor, Oklahoma State University, kridnix@okstate.edu

Lisa Benson, Assistant Professor, Clemson University, lbenson@clemson.edu

October 18 - 21, 2009, San Antonio, TX 